\title{
Research on Cultural Integration in College English Vocabulary Teaching
} Xiuli Yang

Applied Foreign Languages School of Heilongjiang University, Harbin 150080, Heilongjiang, China.

Abstract: Language and culture are inseparable. The cultural connotation behind the language is one crucial element in understanding one language precisely. Integration of culture into college English vocabulary teaching are surely a great help for students to learn and grasp the accurate meaning of English vocabularies. This paper explains the necessity of cultural integration in college English vocabulary teaching, elaborates the obvious differences behind English and Chinese vocabularies, and finally focuses on the effectiveness analysis of measures for cultural integration in college English vocabulary teaching. Keywords: College English; Vocabulary Teaching; Cultural Integration

Students need to master extensively vocabularies in order to effectively learn English well. In general, in the process of imparting knowledge to students, college English teachers need to explain the extracurricular words related to the text. However, many students hold that vocabulary involved in class is far less important than that of grammar, which lead to students more eager to learn grammar instead of vocabularies. Therefore, how to integrate culture into English vocabulary teaching is a very important topic for college teachers to investigate.

\section{The necessity of cultural integration}

Language is a kind of cultural mirror, which has rich cultural significance. Among the many elements of language, the relationship between vocabulary and culture is inseparable. In language, vocabulary is not only the most active component, but also the component of culture. In different languages, words with the same surface meaning are expressed, but the hidden meanings of these words usually differ. For example, it is probably because of differences in religion and morality that different ethnic groups still have different ways of understanding. Such as words with "dog", in the Chinese culture of idioms mostly partial derogatory, such as "a coward" or "snobbish", for the foreign culture, dog is human's good friend, a symbol of loyalty. So in western culture, most proverbs about dog are good. It can be "love me, love my dog", and can also be a "lucky dog". Thus it can be seen that a nation's cognition can determine the differences in lexical culture. And in the process of language learning, vocabulary learning is one important part, especially in college English classroom teaching. Therefore, in order to enable students to better grasp the language knowledge and understand the vocabularies accurately, teachers should effectively integrate the culture into the classical and traditional teaching.

\section{The significant differences between English and Chinese vocabularies}

\subsection{Words have different associative meanings}

Due to cultural differences, Chinese and English languages have different perspectives to describe small animals, natural

This is an open-access article distributed under the terms of the Creative Commons Attribution Non-Commercial License (http://creativecommons. org/licenses/by-nc/4.0/), which permits unrestricted non-commercial use, distribution, and reproduction in any medium, provided the original work is properly cited. 
phenomena and color associations. People with different cultural backgrounds have different ways to understand the same things. For example, the word "dragon", the Oriental dragon is noble, and it is the totem of the Chinese nation. However, the western dragon is the mount of the demon "Satan" or "The Devil" and is regarded as the symbol of the devil. As for the word "white", its associative meaning in Chinese is quite different from in English. In Chinese culture, "white "represents the lack of life or exhaustion of life, while in western culture, white represents nobleness and elegance, and it is considered a good day. ${ }^{[1]}$

\subsection{Different connotations of corresponding words}

Due to the differences in national cultures, many words bear national characteristics. For example, there are words about Chinese medicine in Chinese: heart and lung, etc. From the literal point of view, they can be translated into each other. However, from the perspective of Chinese medicine theory, these words mainly highlight the functional characteristics of each organ. So the literal translation can not fully convey the connotations of the words concerning Chinese medicine. There are also some common western words, such as sandwich, motel, etc. To understand these words, one needs to have some knowledge about western life. Students can not clearly understand these words only depending on the literal translation. ${ }^{[2]}$

\subsection{Different words are positive or negative}

There are a lot of vocabularies, surface meaning of which is the same, but not the same in the hidden meaning. And it requires students to put their own unique background culture into consideration to really understand and use it better. For example, in English words, it is used to describe people's body shape: fat is a derogatory word in western eyes. It would be impolite to use it to describe people. "Heavy" can be used to describe a person's body. It is more neutral and is used to describe a person's body without embarrassment. Another positive way to describe a person's body type is chubby, which means chubby and chubby. But the skinny word can describe people who are too skinny and skinny. It's a negative word. But the word thin tends to be neutral, meaning that a person is thin. The positive word for a person's body shape can be slim, which means slim and slender. They seem to mean the same thing on the surface, but there are still big differences in the actual communication process.

\section{Measures of cultural integration in college English vocabulary teaching}

\subsection{Pay attention to the difference of associative meaning between Chinese and English}

Since the description in English and Chinese language about small animals, nature and the meaning of color vocabulary related to image is different, the teacher should be focusing on, when making vocabulary classroom teaching, the cultural meaning of vocabularies, need to teach the students the specific examples, and cultivate their interest in the meaning behind to ensure the students study vocabulary effectively. Thus, enthusiasm for the students to learn English vocabulary can be effectively stimulated. For example, when meeting with sentences such as "as strong as an ox" and "everyone can be proud", the teacher can first ask the students independently translate, stimulate the students' ability to think about such words, then correct their translation mistakes such as "It's as powerful as a cow and Everyone will be satisfied".${ }^{[3]}$ For example, when the teacher taught the students the word "tea", black tea should be used instead of "red tea" to prevent them from making similar mistakes again. ${ }^{[4]}$

\subsection{A correct view of cultural language should be established}

The establishment of cultural view of language indicates that we should observe language from the perspective of culture and take the language system as an element of the cultural system. The syllabus of college English points out that students should have the ability of listening, speaking, reading and writing as well as the knowledge of foreign language culture, so as to meet the needs of social development and economic construction.

When English learners communicate with foreigners, they will encounter many communication barriers, which may be that they ignore the cultural differences in vocabulary and fail to think in another way. Therefore, students need to learn to have an effective understanding of the meaning and culture behind English words, and it is very important to try to understand its 
connotation. In the process of actual English vocabulary teaching, teachers not only need to know the literal meaning of the words, but also need to understand the cultural connotations involved in the vocabulary, so that students can use the vocabulary correctly. $^{[5]}$

\subsection{Concretize the explanation of connotation of non-corresponding words}

Because there are many non-corresponding words in English and Chinese, we need to visualize and concretize the words when we learn English vocabulary. ${ }^{[6]}$ Teachers can use audio-visual teaching method to make the students understand the word in more vivid way. For example, the teacher can use the video and images such as pictures, to develop their intuitive feelings, thus to deepen the impression of words effectively. Take it for one example, teachers can show students words such as sandwiches and motels in the form of pictures, so that students can have a more effective understanding of the words and improve their ability to use the language. More realistic situations can encourage students to experience and use the language in a reasonable way, stimulate their students' interest effectively, and eventually realize the transition from knowing the words to mastering them completely. Teachers can apply western culture, such as art and architecture, to classroom teaching and induce students to observe western culture.

\section{Conclusion}

To sum up, this paper mainly studies the measures of cultural integration in college English vocabulary teaching through three aspects: emphasis on the differences in associative meanings between English and Chinese, establishment of correct cultural language views and the concretization of the explanation of non-corresponding words.

\section{References}

1. Yao Y. The acquisition of cultural connotation should be emphasized in the teaching of comprehensive English vocabulary in universities. Journal of Taiyuan normal university (social sciences edition) 2011; 10 (06): 164-166.

2. Zhang M, Li N. Vocabulary teaching strategies and effects of basic English. Journal of Anshun college 2008; (03): 49-50+61.

3. Zeng Z, Zhao F. Reflection on the mapping between vocabulary and culture. Journal of Hubei university of economics (humanities and social sciences edition) 2008; (09): 130-131.

4. Xi R. The three-dimensional integration of "Chinese style" into English learning and teaching. Journal of Inner Mongolia normal university (education science edition) 2019; 32(07): 111-117.

5. Jiang X. A study on the integration of mother tongue culture into "college English" classroom teaching. Journal of Lanzhou university of education 2013; 29(04): 88-90.

6. Liu S. A study on the integration of traditional Chinese culture into college English teaching-A case study of tea culture. Fujian tea 2008; 40(10): $176+179$. 